\title{
Progress in the Chemistry of Naval Stores, 1920-1921
}

By F. P. Veitch and V. E. Grotlisch

Chemist in Charge and Assistant Chemist, Leather and Paper Laboratory, Bureau of Chemistry, Washington, D. C.

$\mathrm{D}$ URING the past two years there have been numerous contributions to our knowledge of the chemistry of naval stores, of which oil or spirits of turpentine and rosin are the most important. Probably because of its more widespread and divers uses, and also because of the fact that its composition and constitution are less well understood than is the case with turpentine, more work has been done on rosin than on turpentine. Even now the constitution and exact composition of rosin are not definitely settled. We shall consider the subject at hand under three major headings: first, the crude resin or gum; second, turpentine oil or its constituents and closely related compounds; and third, rosin and its products.

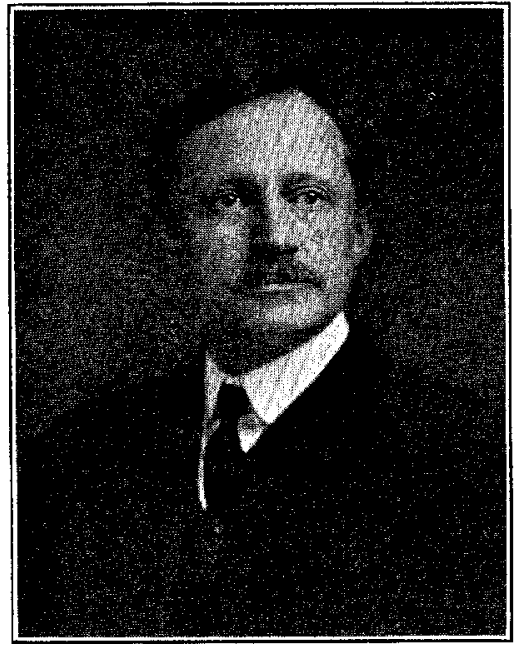

F. P. VEITCH
Resin and Gum

Among the less well-known sources of turpentine and rosin are the pine forests of China. There is quite an appreciable quantity of rosin exported from China, principally to Japan and Australia. Shinosaki and Ono ${ }^{1, * *}$ obtained the following results from a sample of crude Chinese resin: essential oil, 8.5 per cent; rosin, 84.35 per cent; loss, impurity, and water, 7.5 per cent. The essential oil consisted largely of $l$ - $\alpha$-pinene, with a trace of dipentene and about 11 per cent of a new tricyclic sesquiterpene. Heurich ${ }^{2}$ has examined the oleoresin from the Norway pine, $P$. sylvestris, the source of turpentine in Germany, Poland, and Russia. The yield of essential oil and rosin, as well as their composition and properties, is stated to correspond to those of American turpentine and rosin, except that the oil is levorotatory, in this respect simulating French turpentine. A possible new source of naval stores in India is the tree known as Boswellia serrata, or Salai tree. The resinous exudation, known locally as salaigugul, is a gum-resin containing, beside essential oil and rosin, about 20 per cent of soluble gum. Fowler and Malandkar ${ }^{3}$ have worked out a method of separating the rosin and the gum, after removal of the oil by steam distillation, in which the resin is hydrated by heating with water under pressure. The hydrated resin floats on the surface and can be removed as a solid on cooling. The gum forms a flocculent precipitate on the bottom of the vessel. It has weak adhesive power. The hydrated resin is subsequently dehydrated by heating. It differs from ordinary pine rosin principally in acid and saponification numbers, which are, respectively, 51.6 and 61.3. These low values make the rosin useless for soap making, but it may be useful for varnish making.

\footnotetext{
1 Published by permission of the Department of Agriculture.
}

* Numbers in the text refer to Bibliography at end of paper.
In a series of articles, G. Dupont $4,5,6$ describes the results of his investigations on the resin of the French maritime pine. The two isomeric acid constituents, $d$ - and l-pimaric acids, show marked difference in the stability of their rotatory power. The rotation of $d$-pimaric acid was not

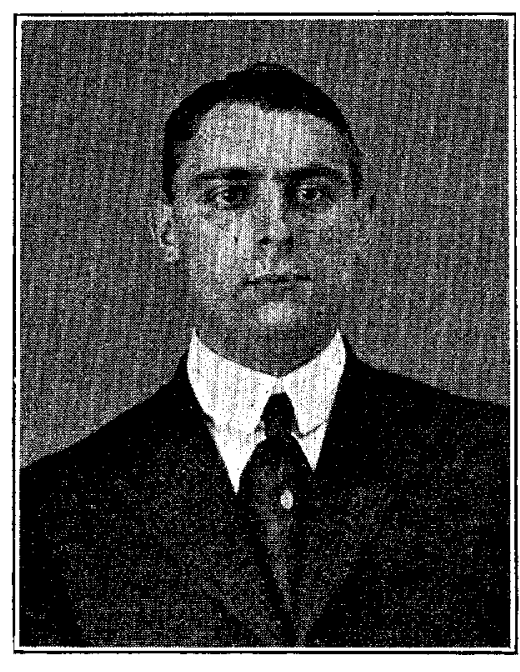

V. E. GRothisch changed by the action of very dilute $\mathrm{HCl}$, but $l$-pimaric acid showed decreasing rotatory power according to the length of time in contact with the hydrochloric acid, up to 24 hrs., after which the rotation increased again slightly. $\mathrm{He}$ considers the abietic acid in rosin as a mixture of isomorphous acids which he designates as pimarabietic acid, produced by the action of heat on the pimaric acids of the crude resin.

\section{Turpentine}

The terpenes, of which pinene, the principal constituent of turpentine, is probably the best known, constitute a large and complex class of compounds. Only those bearing a direct relation to turpentine and its constituents are considered in this review. Simonsen ${ }^{7}$ has found a new bicyclic terpene, $d$-carene, and a new tricyclic sesquiterpene, which he calls longifolene, in the Indian turpentine oil obtained from the Chir pine, $P$. longifolia. The author ascribes to these two new compounds the two properties of Indian turpentine which make it inferior to the American or French product, namely, ease of oxidation and high per cent of residue on evaporation. Although not oxidized by a mixture of dichromate and sulfuric acid, $d$-carene readily absorbs oxygen from the air, as shown by the fact that one cc. of this compound, when placed in a closed vessel (dimension not stated), absorbed all the oxygen from the air in three days. Analytical constants for the new compounds are given.

The preparation of synthetic rubber and synthetic camphor has occupied the attention of chemists, more particularly in Europe, for many years. If economically successful, it would open up a wide field for the use of turpentine. In order to throw some light on the conditions governing the formation of isoprene, as well as to check up a theory advanced some years ago that limonene or dipentene gives better yields of isoprene than pinene, Mahood $^{8}$ passed the vapors of turpentine, both from gum spirits and steam-distilled wood turpentine, through heated tubes, with and without catalysts, under carefully regulated thermal conditions. His results indicated that limonene, or rather the turpentine fractions consisting largely of limonene, did not give any marked increase in the yield of isoprene, and that gum turpentine was just as good as wood turpentine. The small yields of both isoprene and toluene preclude any economic disposal 
of turpentine in this way. The production of synthetic camphor, however, has shown considerably more promise, from an economic point of view, than the manufacture of synthetic rubber from isoprene. Luttringer and Dubosc, ${ }^{9-16}$ in a series of articles, have described a number of methods of treating turpentine or derivatives thereof, principally pinene hydrochloride, to obtain esters which can be easily converted into camphor. Along this same line, Wesson ${ }^{17}$ has patented a process of converting pinene hydrochloride into isobornyl esters, based on the action of certain organic acids in the presence of zinc as a catalyst. An interesting review of the patent literature on the manufacture of synthetic camphor has been published by Witte, ${ }^{18}$ the author going back to some of the earliest patents taken out in Germany. The practicability of some of the patents, in the light of our present knowledge on the subject, is also discussed. The Fabrique de Prod. Chim. de Thann et Mulhouse ${ }^{19}$ has patented in England a process for obtaining optically active borneol, free from isoborneol, based on the reaction of pinene and tetrachlorophthalic acid.

Pariselle ${ }^{20}$ has separated $\alpha$ - and $\beta$-pinene from a large volume of French turpentine by very careful fractionation in vacuo, and checked up their physical constants. By the action of hydrogen bromide both compounds gave the same two hydrobromides, one solid and the other liquid. Bromine in carbon tetrachloride solution, at low temperature, gave a complex mixture of addition and substitution products, containing both bromides and hydrobromides. A monobromide and two dibromides were isolated.

Henderson and Marsh ${ }^{21}$ obtained three pinene dichlorohydrins, soluble in water, by the action of a dilute aqueous solution of hypochlorous acid on pinene. In one of the papers of their extended series on the chemistry of pinene, Ruzicka and Trebler ${ }^{22}$ dispute the constitutional formula for nitrosopinene advanced by Wallach, and advance one based on their own observations.

\section{ANaLYsis}

The analysis of turpentine is largely confined to detection and estimation of adulterants and for compliance with specifications. Hofman ${ }^{23}$ has described a simple method of detecting adulteration of certain essential oils, among them being turpentine. These oils are relatively insoluble in alcohol at ordinary temperatures. The oil is dissolved in four volumes of alcohol by warming, the concentration of the alcohol depending upon the oil under observation. Ninety per cent alcohol is used for turpentine. If the turpentine is pure, the solution should start to become turbid, indicating separation, at about $60^{\circ} \mathrm{C}$. Allina and Salvaterra $^{24}$ and Salvaterra ${ }^{25}$ have described methods of determining mineral oil in turpentine, for which they claim greater accuracy than is shown by most of the practical methods now in use. Their methods are based on the formation of nonvolatile compounds by the absorption of bromine or iodine by the terpenes to the point of complete saturation. The volatile unchanged mineral oil is then removed by steam distillation. The application of the methods (especially Salvaterra's iodine method) is rather expensive, however, on account of the high cost of the reagents used, since turpentine absorbs over three times its weight of iodine, and considerable excess must be used to insure complete reaction.

Very few methods have been published on the determination of coal-tar oils, such as toluene, xylene, and solvent naphthas, in turpentine, probably on account of the relative infrequency of such adulteration. Grotlisch and Smith ${ }^{26}$ have worked out a method which is not only applicable to adulteration with small percentages of coal-tar oil, but also detects the presence of mineral oil. Some of the pinene of the turpentine is removed by conversion into the solid pinene hydrochloride, and the adulterant concentrated by fractional distillation of the filtrate at reduced pressure. The distillate containing the adulterant is then sulfonated to destroy the remaining terpenes and to form sulfonic acids of the coal-tar hydrocarbons. Steam distillation of the sulfonation mixture separates any unchanged mineral oil that might be present. Finally, the sulfonic acids of the coal-tar hydrocarbons are broken up with recovery of the oils themselves, by direct heat distillation.

Specifications for turpentine have heretofore been far from uniform. Based on the results of examining a considerable number of commercial pure turpentines, the U. S. Interdepartmental Committee on Paint Specification Standardization ${ }^{27}$ has adopted and published a set of "Recommended Specifications for Turpentine," which have been adopted by various bureaus of the Government and other agencies as standard specifications for turpentirie. Instructions for sampling, analysis, preparation of reagents, and a basis of purchase, which take account of the expansion and contraction of turpentine with changes in temperature, are given. A handbook on turpentine has been published by Veitch and Grotlisch ${ }^{28}$ containing, besides the above specifications, a review of the principal sources of turpentine throughout the world, the principal uses, process of manufacture, methods of transportation, expansion tables, simple methods of detecting adulteration, review of state laws covering the sale of turpentine, statistics on production and exports, and a method of calculating capacity and outage of tanks.

\section{Uses of TURPENTINE}

By far the largest proportion of turpentine is used as a thinner in paint and varnish. Several interesting new uses have recently been described. An anonymous article ${ }^{29}$ describes the use of turpentine in a bleaching liquor said not to affect the strength of the fiber of the cloth, as chlorine often does. Several formulas for preparing the "ozonized" turpentine are given. Another interesting new use is described in a patent by Pratt. ${ }^{30}$ A sulfur-terpene compound known as "toron," in the form of a black viscous liquid or semisolid, is prepared by heating turpentine with sulfur. It is used for waterproofing canvas, preparing rubberized cloth, and as a bond for attaching or coating metal surfaces with genuine rubber. The physiological effects of turpentine vapors when turpentine is used in quantity as an extraction medium for fats, waxes, etc., are discussed by Lewin. ${ }^{31}$ Turpentine is classed as a narcotic type, producing depression of the nervous system, and may cause eruption of the skin and mucous membrane.

\section{Rosin}

One of the less well-known constituents of rosin is a body called retene. Virtanen ${ }^{32}$ has attempted to throw some light on the relationship between retene and the resin acids by preparing hydrogenated retenes and studying their chemical properties. One peculiarity brought out is the stability of the hydrogenated retenes toward permanganate, although they are unsaturated bodies. Aschan and his co-workers ${ }^{33,34,35}$ have described and investigated a new resin acid, called pinabietic acid, which they obtained from a Swedish pine oil. Its molecular weight indicates the formula $\mathrm{C}_{20} \mathrm{H}_{80} \mathrm{O}_{2}$, thus being isomeric with abietic acid. It does not, however, show the same color reaction by the Macht test as abietic acid. A striking peculiarity is the difference in rotation in various solvents. It is dextrorotatory in the aromatic

\footnotetext{
$\dagger$ Monatsh., 15 (1894), 627.
} 
hydrocarbons, and levorotatory in alcohols, ether, and chloroform. By adding absolute alcohol to the solution in benzene, the rotation can be changed from positive to negative, with a zero reading in a mixture of 92 per cent of benzene and 8 per cent of alcohol. It is nearly insoluble in petroleum ether and ligroin. A constitutional formula is given.

Aschan $^{36}$ claims to have discovered and describes a new series of acid bodies in rosin which he calls colophenic acids, with a general formula $\mathrm{C}_{n} \mathrm{H}_{2 n-10} \mathrm{O}_{4}$. Several methods of separating them from rosin are described. The author believes that it is owing to the presence or formation of these acids that the dark color of low-grade rosins, as well as the bitter taste, is due. The dark color of the "leim-galle," the precipitate which forms on boiling a solution of rosin size, is also supposed to be due to these bodies. They are amorphous, highly unsaturated, and instantly decolorize permanganate. Fahrion ${ }^{37}$ has taken issue with Aschan as to the originality of the discovery of these bodies in rosin. $\mathrm{He}$ claims that they are identical with the so-called oxyabietic acids described by him in a previous work $\dagger \dagger$ on the atmospheric autoxidation of powdered rosin. In a later article Aschan ${ }^{38}$ refutes Fahrion's claim to priority, and shows that there is no relation between Fahrion's oxyabietic acid and the colophenic acids.

Grün, ${ }^{39}$ on the basis of his observations, has attempted to formulate a structural formula for abietic acid to show its relation to $\alpha$ - and $\beta$-pinene. He discusses the possibility of the formation of abietic acid by the union of one molecule each of $\alpha$ - and $\beta$-pinene. Stock ${ }^{40}$ has distilled rosin under the high vacuum of the green cathode ray, $i$. e., practically a complete vacuum. It was possible to distil it almost completely without appreciable decomposition. The relatively small difference in temperature between the boiling liquid rosin and the vapors proves that rosin does not contain polymerized bodies of abnormally high molecular weight. $\mathrm{He}$ obtained crystalline acids from amorphous rosin by heating in vacuo, the time required to effect complete change depending on the temperature used. Among his conclusions is the following on the composition of rosin: $\alpha$-abietic acid, 31 per cent; $\beta$-abietic acid, 31 per cent; $\gamma$-abietic acid, 19 per cent; resenes (or retenes) 10 per cent; essential oil and bitter principles, 0.5 per cent; impurities, 0.5 per cent.

\section{ANALYsis}

The detection and determination of rosin in mixtures and preparations is probably the most important phase of rosin analysis, since it is seldom bought on specification and not much subject to adulteration. Wolff ${ }^{41}$ has described a method of detecting and approximately estimating the rosin in oil varnishes. He finds it necessary to isolate the resin acids, since boiled linseed oil, especially in the presence of manganese driers, sometimes gives a reaction with the Storch-Morawski test which closely approaches that of rosin. Neither rosin which has been heated to high temperature for some time nor rosin esters give a characteristic color test. McNicoll ${ }^{42}$ has published a method for determining resin acids in fatty mixtures, depending on the esterification of the fatty acids by naphthalene- $\beta$-sulfonic acid, leaving the resin acids unchanged. These are titrated or separated and determined gravimetrically. More reliable results are claimed than by former methods, such as Twitchell's.

\section{Use of Rosin}

The three principal uses of rosin in order of their importance in the United States are the manufacture of soap, paper size, and varnish, soap makers using about as much as the

i† Z. angerw. Chem., 20 (1907), 356. other two industries together. A bibliography on the use of rosin in soap-making has been published by Jungkunz, ${ }^{43}$ which also includes a discussion of the methods of determining rosin in soap. German rosins, prepared in Germany from the resin of $P$. sylvestris, seem not to have measured up to the imported American and French products, especially from the soap-makers' standpoint. Goldschmidt and Weiss ${ }^{44}$ have examined several samples of German pine resin, from which they prepared the rosin by the use of solvents. 'Their analysis of these brings them to the conclusion that German rosin is not greatly inferior to American or French rosin, so far as acid and saponification values and per cent of unsaponifiable are concerned. Goldschmidt ${ }^{45}$ found that rosin, when left in lump form, showed up better on the "stearin" method*for available rosin substance, $i$. e., the soap-making power or value of the rosin, than powdered rosin. They conclude, from the results obtained on powdered rosin which was exposed to moist air for some time, that a watersoluble oxidation product is obtained, which is lost during the analysis by escaping solution with other resin acids in the ether.

The application of rosin to the sizing of paper has brought out a number of new ideas. Thindon ${ }^{48}$ concludes from recently published data that the sizing property of rosin is due to free rosin which in turn is protected by a film of aluminium hydroxide or resinate. Traquair ${ }^{47}$ states that by dissolving the size and alum in a suitable starch solution the quantity of rosin required can be reduced by about 50 per cent. Sutermeister ${ }^{48}$ seems to think that high-grade rosins gave better sizing efficiency than low grade, but the difference between them hardly warrants the payment of any material difference in price.

Sieber ${ }^{49}$ has investigated the behavior of a suspension of free rosin toward various electrolytes. The suspension was precipitated by $\mathrm{Al}_{2}\left(\mathrm{SO}_{4}\right)_{3}$ at a concentration of 0.00261 mols. per liter. Calcium and magnesium salts required 0.025 and 0.015 mols. per liter, respectively, to precipitate the rosin. From this he concludes that hard water does not materially affect the suspension of free rosin. Schneider ${ }^{50}$ also discusses the bad effect of hard water on size emulsions containing a high percentage of free rosin, and further points out that a size emulsion should not get above $100^{\circ} \mathrm{F}$., since aluminium resinate starts to solidify or coagulate at this temperature, losing its finely divided form. Miles ${ }^{51}$ has taken out a patent for oxidizing rosin by agitation with $\mathrm{H}_{2} \mathrm{O}_{2}$ until it is capable of forming an ammonium compound which may be diluted indefinitely with water, thus being adapted to paper sizing.

Within the past five or six years the use of rosin in varnishmaking has increased markedly, owing to the discovery that rosin could be esterified, reducing its acid value and increasing its hardness and weather resistance. Very satisfactory varnishes are now made from rosin esters and tung oil. Gardner and Coleman ${ }^{52}$ have described a process for the esterification of rosin with glycerol and tung oil in the open varnish kettle, using hydrated lime or calcium soaps as catalysts. Formulas for several different classes of varnish are given.

Sterling, Grotlisch, and Veitch ${ }^{53}$ have patented a process of esterifying rosin with glycerol using zinc as a catalyst, whereby very low acid values are obtained. Murray ${ }^{4}$ has investigated the various conditions governing the esterification of rosin with glycerol. A very satisfactory product is obtained by esterifying with somewhat less than the required quantity of glycerol for complete neutralization, and completing the latter with lime. An interesting point brought out is the fact that a good rosin ester approaching kauri can be ob-

* Goldschmidt and Weiss, Seifenfabr., 39 (1919), 49; C. A., 13 (1919), 1942. 
tained by esterifying a mixture of one part rosin and three parts congo copal, but the process must be carried out in an aluminium vessel instead of copper, since the latter acts in a catalytic manner, setting the mixture of resins before esterification can take place.

$\mathrm{Jahn}^{55}$ has examined the properties of mixtures of rosin and beeswax, and found that under certain conditions solid solutions are formed, or mixtures in which the solid solution of rosin in wax is in equilibrium with pure wax. Changes taking place on storage of such mixtures are described. Gerstacker ${ }^{60}$ has examined what he terms a "distilled rosin," the residue or product obtained by only partially breaking down rosin and volatilizing the oil formed. He gives the properties of the bodies obtained by heating the rosin at $310^{\circ}$ to $320^{\circ} \mathrm{C}$. and at $350^{\circ}$ to $370^{\circ} \mathrm{C}$. Strange to say, the latter product is the harder of the two. Neither is entirely soluble in a mixture of alcohol and chloroform.

\section{Miscellaneous}

Hübscher ${ }^{57}$ describes a product obtained in Sweden as a by-product in the manufacture of chemical wood pulp, which is known as "tall-öl," or Swedish rosin oil or pine oil. The crude product is refined by distillation leaving a so-called "tall-öl pitch." Recipes for using the products are given.

Shippen and Griffen ${ }^{58}$ have investigated the properties of emulsions made from pine oil and other oils obtained by the distillation of pine wood, with reference to their value as antiseptics and bactericides, along the line first pointed out by Stevenson.** They substantiate some of the earlier findings of Stevenson, notably that steam-distilled pine oil gives a more active disinfectant than the destructively distilled oils. They conclude, however, that disinfectants of this type have only a limited value, since they failed to kill Micrococcus aureus and $B$. anthracis in any dilution capable of emulsification. For killing $B$. typhosus in a limited time, a dilution of $1 / 100$, or 1 per cent, is recommended even though a $1 / 500$ dilution killed when in contact with the organism for a longer time.

\section{BIBLIOGRAFHY}

$1-\mathrm{Y}$. Shinosaki and T. Ono, "Chinese Pine Resin and Gum." J. Chem Ind. (Japan), 23 (1920), 45; C. A., 14 (1920), 2928.

2-Ir. Fleurich, "On the Constituents of the Gum of Pinus sylvestris." $Z$, angew. Chem., 134 (1921), 363.

3-G. J. Fowler and M. A. Malandkar, "Extraction of Turpentine, Resin, and Gum from the Gum Oleoresin of Boswellia serrata." J.Ind. Inst. Sci., 4 (1921), 27.

4-Georges Dupont, "Acid Constituents of Pine Resin, $d$ - and $l$-Pimaric Acid." Compt.rend., 172 (1921), 923.

5-G. Dupont, "Composition of Pimaric Acid." Ibid., 172 (1921), 1184.

6-G. Dupont, "Isomerization of the Pimaric Acids." Ibid., 172 (1921), 1373.

7-J. I. Simonsen, "Constituents of Indian Turpentine from Pinus longifolia." J. Chem. Soc., 117 (1920), 570.

8 -S. A. Mahood, "Thermal Decomposition of Turpentine." J.Ind. Eng. Chem., 12 (1920), 1152.

9-A. Luttringer and A. Dubose, "Preparation of Bornyl Formate." Bull. soc. ind. Rouen, 48 (1920), 84.

10-A. Iuttringer and A. Dubosc, "Action of Formic Acid on Dry Pinene Hydrochloride." Ibid., 48 (1920), 84.

11-A. Dubose and A. Luttringer, "The Preparation of Camphor from Oil of Turpentine by Means of Salicylic Acid and an Alkaline Peroxide." Ibid., $48(1920), 85$.

12-A. Dubose and A. Luttringer, "Preparation of Bornyl Formate by the Action of Sodium Formate and Powdered Zinc on Solid Pinene Hydrochloride." Ibid., $48(1920), 85$.

13-A. Dubose and A. Luttringer, "Preparation of Bornyl Formate by the Action of Sodium Formate and Iron Filing on Solid Pinene Hydrochloride." Ibid., 48 (1920), 86.

14-A. Dubose and A. Luttringer, "Preparation of the Bornyl Esters of Propionic, Butyric and Salicylic Acids." Ibid., 48 (1920), 88.

15-A. Dubosc and A. Luttringer, "Preparation of Bornyl Esters and

** U. S. Pub. Health Service, Pub. Health Repts., 30, No. 41 (1915), 3004.
Camphor from Oil of Turpentine, Propionic Acid and an Alkaline Peroxide." Ibid., 48 (1920), 89.

16-A Luttringer, "Synthetic Camphor." Ibid., 48 (1920), 90.

17-L. G. Wesson, "Conversion of Pinene Compounds into Isoborny1 Ester and Camphane Mixture." U. S. Patent 1,372,382 (March 22, 1921).

$18-\mathrm{E}$. Witte, "Camphor Synthesis according to Patent Literature." Chem. Ztg., 45 (1921), 118.

19-Fab. de Prod. Chim. de Thann et Mulhouse, "Preparation of Borneol." Brit. Patent 144,604.

20-A. Pariselle, "Composition of French Oil of Turpentine and $\alpha$-Pinene Bromide." Compt.rend., 172 (1921), 1496.

21-G. G. Henderson and J. K. Marsh, "Action of Hypochlorous Acid on Pinene." J. Chem. Soc., 119 (1921), 1492.

22-I. Ruzicka and Hi. Trebler, "Constitution of Nitrosopinene and Its Transformation Products." Helvetica Chim. Acta., 4 (1921), 556.

23-J. J. Hofman, "Determination of the Separation Temperature of Essential Oils and Alcohol as a Criterion of Purity." Pharm. Weekblad, 57 (1920), 651.

24-A. Allina and H. Salvaterra, "Estimation of Benzine in Turpentine." Chem. Ztg., 44 (1920), 673, 697.

25-H. Salvaterra, "New Methods of Examination of Turpentine Oil." Ibid., 45 (1921), 133, 150, 158.

26-V. E. Grotlisch and W. C. Smith, "Detection and Estimation of CoalTar Oils in Turpentine." J. Ind. Eng. Chem., 13 (1921), 791.

27-P. H. Walker, Chairman U. S. Interdepartmental Committee on Paint Specification Standardization, "Recommended Specifications for Turpentine." U. S. Bur. Stds., Circ. 86, February 16, 1920.

28-F. P. Veitch and V. E. Grotlisch, "Turpentine: Its Sources, Properties, Uses, Transportation and Marketing." U. S. Dept. Agr., Bull. 898, November 8, 1920.

20-Anonymous, "Various Methods of Augmenting the Energy of Hypochlorites." Textile Mercury, 63 (1920), 63.

30-Wm. B. Pratt, "Sulfur-Terpene Compound." U. S. Patent $1,349,909$ (August 17, 1920).

31-L, Lewin, "Poisonous Extraction Media for Fats, Waxes, etc." $Z$. deut. Ol-Fett-Ind., 40 (1920), 421, 439.

32-A. J. Virtanen, "Relation of Retene to the Resin Acids." Ber., 53B (1920), 1880.

33-O. Aschan, "Pinabietic Acid, a Homogeneous Resin Acid. IOccurrence and Purification of the Acid." Ann., 424 (1921), 117.

34-O. Aschan and K. E. Ekholm, "II-Molecular Weight and Rotatory Power of Pinabietic Acid." Ann., 424 (1921), 133.

35-A. I. Virtanen, "III-Constitution of Pinabietic Acid." Ann., 424 (1921), 150-215.

36-O. Aschan, "New Constituents of Rosin, the Colophenic Acids." Ber., 84 B (1921), 867.

37-W. Fahrion, "On Colophenic Acid." Ber., 54B (1921), 1944.

38-O. Aschan, "On the Colophenic Acids. An Answer to W. Fahrion." Ber., 85B (1922), 1.

39-A. Grün, "Constitution of the Resin Acids of Colophony." $Z$. deut. Ol- Fett-Ind., 41 (1921), 49.

40-E. Stock, "Chemical Constitution of American Rosin." Farben$Z$ tg., 27 (1921), 156, 221, 287, 353, 416.

$41-H$. Wolff, "Detection of Rosin and Its Derivatives in Oil Varnishes." Ibid., $26(1920), 648$.

42-D. J. McNicoll, "Estimation of Resin Acids in Fatty Mixtures." J. Soc. Chem. Ind., 40 (1921), 124T.

$43-\mathrm{R}$. Jungkunz, "Rosin in the Soap Industry." Seifensieder-Ztg., 48 (1921), 563.

44-F. Goldschmidt and G. Weiss, "German Long Needle Pine Rosin."

Z. deut. Ot-Fett-Ind., 41 (1921), 81.

45-F. Goldschmidt, "Change in Powdered Rosin by Action of Air and Moisture." Ibid., 41 (1921), 147.

46-R. Thindon, "Rosin Size Industry." Papier, 23 (1920), 145.

47-J. Traquair, "Colloidal Rosin in Beater Sizing." Paper, 26 (1920), 185.

48-E. Sutermeister, "Rosin and Rosin Sizing." i3id., 27 (1920), 22.

49-R. Sieber, "Rosin Sizing." Zellstoff u. Papier, 1 (1921), 15, 65.

$50-$ C. C. Schneider, "Rosin or Engine Sizing." Paper Trade J., 72 No. 18 (1921), 48.

51-G. W. Miles, "Oxidizing Resin." U. S. Patent 1,401,348 (December 27,1921 ).

52-H. A. Gardner and R. E. Coleman, "Production of Rosin-Tung. Esters in the Open Varnish Kettle." Paint Mfrs. Assoc. of U. S., Spec. Circ. 101, August 1920.

53-W. F. Sterling, V. E. Grotlisch and F. P. Veitch, "Process for Making. Varnish Material." U. S. Patent 1,395,874 (November 1, 1921).

54-A. Murray, "Hardened Rosin and Resin Esters." Chem. Met. Eng., 25 (1921), 473.

55-G. Jahn, "Supersaturated Solid Solutions in Mixtures of Wax and Colophony." Kolloid chem. Beihefte, 13 (1921), 213.

56-L. Gerstacker, "Distilled Rosin." Farben-Ztg., 25 (1920), 1170.

57-J. Huibscher, "Swedish Rosin Oil." Seifensieder-Ztg., 48 (1921), 231.

58-L. P. Shippen and E. L. Griffin, "Pine Oil and Pine Distillate Emulsions." U. S. Dept. Agr., Bull. 989, October 7, 1921. 